\title{
Effect of Lidocaine Pre-Treatment on Protamine-Induced Pulmonary Vascular Reaction During the Repair of Congenital Heart Disease
}

\author{
Hong-Wu Wang ${ }^{l, *}$ \\ Yi-Jin $\mathrm{Hu}^{\mathrm{l}, *}$ \\ Guo-Lin Wang ${ }^{2}$ \\ 'Department of Anesthesiology, TEDA \\ International Cardiovascular Hospital of \\ Tianjin Medical University, Tianjin, \\ 300052, People's Republic of China; \\ ${ }^{2}$ Department of Anesthesiology, General \\ Hospital of Tianjin Medical University, \\ Tianjin, 300074, People's Republic of \\ China
}

*These authors contributed equally to this work
Correspondence: Guo-Lin Wang Department of Anesthesiology, General Hospital of Tianjin Medical University, Tianjin, 300074, People's Republic of China

Tel/Fax +86 I5822855566

Email wangg1698521@I63.com
Background: Protamine is a polycationic, and a strong basic peptide isolated from Clupeidae or Salmonidae fishes' sperm, which is rich in arginine and highly alkaline.

Objective: To explore the effect of lidocaine pre-treatment on protamine-induced pulmonary vascular reaction during the repair of congenital heart disease.

Methods: Eighty patients undergoing repair of congenital heart disease were randomly divided into four groups: $A_{1}$ (non-pulmonary hypertension + lidocaine pre-treatment) group, $\mathrm{A}_{2}$ (non-pulmonary hypertension + normal saline) group, $\mathrm{B}_{1}$ (pulmonary hypertension + lidocaine pre-treatment) group, and $\mathrm{B}_{2}$ (pulmonary hypertension + normal saline) group. Hemodynamic parameters, pulmonary inflammation, and pulmonary function were assessed at six intraoperative time points, two intraoperative time points and three intraoperative time points, respectively. $P$-value $<0.05$ was considered statistically significant.

Results: $\mathrm{A}_{2}$ group exhibited increased PAP, Paw, RI and $\mathrm{A}-\mathrm{aDO}_{2} . \mathrm{B}_{2}$ group exhibited increased Paw, RI and $\mathrm{A}-\mathrm{aDO}_{2}$ and decreased Cydn and $\mathrm{OI}$ after protamine administration. These changes were not observed in $A_{1}$ and $B_{1}$ group. Compared with $A_{1}$ and $B_{1}$ groups, plasma $\mathrm{TXB}_{2}$ level in $\mathrm{A}_{2}$ and $\mathrm{B}_{2}$ group was higher, but 6-keto- $\mathrm{PGF}_{1 \mathrm{a}}$ in $\mathrm{A}_{2}$ and $\mathrm{B}_{2}$ groups was lower. Incidence of protamine adverse reactions in $A_{1}$ and $B_{1}$ group was lower than that in $\mathrm{A}_{2}$ and $\mathrm{B}_{2}$ group.

Conclusion: Precondition of lidocaine before neutralization of heparin may be effective for protamine-induced pulmonary vascular reaction during CHD repair.

Keywords: congenital heart disease, protamine, adverse reactions, extracorporeal circulation, pulmonary hypertension

\section{Introduction}

Protamine is a peptide rich in arginine and highly alkaline. When intravenously injected, protamine interacts with the polyanionic heparin to form a neutral charge 1:1 complex, which isolates heparin from antithrombin III, and leads to the loss of its anticoagulating properties. Therefore, protamine has been often used in cardiac and other surgeries to confront anticoagulating heparin. ${ }^{1}$

However, protamine can bring risks to patients, including severe adverse hemodynamic effects of heparin neutralization by protamine, such as catastrophic pulmonary vasoconstriction and systemic hypotension, which may rarely occur, but are often life-threatening. ${ }^{2}$ In addition, its toxicology is also due to its interaction with the peptides on the surfaces of the vasculature and blood cells, which involves membrane receptors and ion channels targeted by different vasoactive compounds. ${ }^{3}$ 
Even though the detailed mechanism of the toxicology of protamine remains unclear, protamine's interaction with immunoglobulins and the activation of the complement system, ${ }^{4}$ which triggers the release of a wide variety of inflammatory mediators, are associated with the development of the vast majority of adverse effects, ranging from minor hemodynamic instability to life-threatening anaphylactic incidents and fatal cardiovascular collapse. ${ }^{5}$ Regardless of the poor therapeutic index and being considered to be a common risk factor for life-threatening events in cardiac surgery, protamine remains the mainstay drug for heparin neutralization. In the study conducted by Guan et al, five cases had severe pulmonary vasoconstriction in a total of 4,160 cases in cardiac surgery from January 2012 to December 2016, which means that the incidence is 1 per $832(5 / 4160){ }^{6}$

Lidocaine is the most commonly used local anesthetic in clinical practice. In addition to blocking the inhibitory effects of the nerve signal, lidocaine has a regulatory function in the immune system, which have been proven to be beneficial in multi-links of inflammatory response. Due to its significant anti-inflammatory characteristics, lidocaine can alleviate acute lung injuries caused by various reasons. $^{7}$

To date, no data are available regarding the value of lidocaine in pulmonary vascular reactions induced by protamine during the repair of congenital heart disease. In order to address this relative lack of information, the present prospective clinical study was performed, aiming to provide a theoretical basis for clinical drug use.

\section{Materials and Methods}

\section{Ethics Information}

The study was conducted in accordance with the Declaration of Helsinki (as was revised in 2013). The study was approved by Ethics Committee of the TEDA International Cardiovascular Hospital. A written informed consent was obtained from all patients (children over 10 years old) and their guardians (such as their parents) included in the present study. All the patients recruited in this study were children with simple congenital heart disease and did not receive norepinephrine and other vasoconstrictive drugs after surgery. After the cardiopulmonary bypass was stopped, the patients with pulmonary hypertension would be selectively assisted with milrinone at a dose of $0.5 \mathrm{ug} / \mathrm{kg} . \mathrm{min}$.

\section{Subjects}

From June 2018 to February 2019, a total of 80 patients, who fell into ASA physical status I or II, were within 1-12 years old, weighed $\geq 10 \mathrm{~kg}$, had no gender limitation, and underwent elective congenital heart disease correction with cardiopulmonary bypass $(\mathrm{CPB})$, were prospectively selected.

The inclusion criteria included the following: initial operation patients, non-cyanotic congenital heart disease, no infectious diseases before the operation, and no abnormalities found in the heart, lung, liver and kidney, and in coagulation function. The exclusion criteria included the following: history of protamine exposure, protamine allergy, preoperative respiratory disease, preoperative hemodynamic instability, emergency surgery, respiratory and circulatory accidents occurring during anesthesia induction, patients with intraoperative cardiac dysfunction or some special reasons leading to the extension of CPB time or operation time, and other test subjects.

Depending on whether pulmonary hypertension was directly measured in the pulmonary artery by a cardiac surgeon, and whether lidocaine $(2 \mathrm{mg} / \mathrm{kg})$ pre-treatment was given before protamine neutralization, all patients were randomly divided into four groups using the random table method, with 20 patients in each group: $\mathrm{A}_{1}$ (nonpulmonary hypertension + lidocaine pre-treatment) group, $\mathrm{A}_{2}$ (non-pulmonary hypertension + normal saline) group, $\mathrm{B}_{1}$ (pulmonary hypertension + lidocaine pre-treatment) group, and $\mathrm{B}_{2}$ (pulmonary hypertension + normal saline) group. According to the ratio of pulmonary/systemic circulatory pressure, ${ }^{8}$ a ratio of $\leq 0.3$ was considered normal, while the ratio $>0.3$ was considered as pulmonary hypertension.

\section{CPB Operation}

After a standard median sternotomy procedure and heparinization with a bolus dose of $3 \mathrm{mg} / \mathrm{kg}$ heparin, the ascending aorta and vena cava was cannulated for arterial perfusion and venous drainage, respectively. The CPB technique was standardized. An initial dose of heparin ( $3 \mathrm{mg} / \mathrm{kg}$ ) was administered before CPB, and supplemental heparin was given into the $\mathrm{CPB}$ circuit for systemic anticoagulation effect, maintaining the activated clotting time (ACT) at above 480 seconds. The target CPB flow was 2 $\mathrm{L} / \mathrm{min} / \mathrm{m}^{2}$, and the target pressure was $>30 \mathrm{mmHg}$. Moderate hypothermia (anal temperature at $28-30^{\circ} \mathrm{C}$ ) was maintained. Protamine sulfate was used in the study. 
All children were induced with cisatracurium benzosulfonate at a loading dose of $0.1 \mathrm{mg} / \mathrm{kg}$, continued intravenous pumping during the operation and a maintenance dose of $0.12 \mathrm{mg} / \mathrm{kg}$.h. TOF value was not measured intraoperatively. Mechanical ventilation settings were the same for all patients. Inhaled oxygen concentration (FiO2) was 40 $70 \%$, oxygen flow rate was $2 \mathrm{~L} / \mathrm{min}$, respiration rate was 16-30 times, tidal volume (VT) was $8-10 \mathrm{~mL} / \mathrm{kg}$, aspiration/respiration ratio was $1: 2$. PTC02 $35-45 \mathrm{~mm} \mathrm{Hg}(1 \mathrm{~mm}$ $\mathrm{Hg}=0.133 \mathrm{kPa}$ ) was maintained and respiratory parameters were adjusted according to the results of intraoperative blood gas analysis.

Before cutting skin, before connecting, thawing, protamine neutralization moments before intravenous sufentanil, respectively, midazolam, with inhaled sevoflurane, continuous pump injection of propofol, right the microphones, shun benzene sulfonic acid atracurium maintain anesthesia, intraoperative continuous observation of heart rate (HR), invasive arterial blood pressure, breathing, EEG double-frequency index (BIS) value, etc., maintain BIS value of 40-60; other hemostatic drugs, such as hemagglutinase, tranexamic acid and fibrinogen, should be used to control bleeding tendency after surgery. Blood gas analysis, electrolytes and hemoglobin should be monitored. Blood transfusion should be performed in strict accordance with blood transfusion indications.

After the relapse, the children were given anisodamine, atropine, dopamine, milrinone and other auxiliary drugs according to their cardiac function and rhythm. According to the results of arterial blood gas analysis, electrolyte disturbance and acid-base balance were corrected in time to maintain the internal environment stability, and the patient was stopped gradually when the hemodynamics was stable In this study, all the children recruited had simple congenital heart disease with good cardiac function, and no vasoactive drugs such as dopamine and epinephrine were used after surgery. Patients with persistent pulmonary hypertension after surgery were supplemented with milrinone $0.5 \mathrm{ug} / \mathrm{kg} . \mathrm{min}$ continuous pump.

\section{Diagnostic Criteria of Protamine-Induced Adverse Reactions}

All patients were successfully and easily weaned from CPB. After hemodynamic stability was established, following adequate volume loading with pumping of blood, the $\mathrm{A}_{1}$ and $\mathrm{B}_{1}$ groups received lidocaine $(2 \mathrm{mg} / \mathrm{kg}$ ) directly via a $\mathrm{BD} 22 \mathrm{G}$ intravenous indwelling needle placed into the pulmonary artery by a cardiac surgeon at one minute before heparin neutralization, and with the same manner, the $A_{2}$ and $B_{2}$ groups received normal saline $(2 \mathrm{mg} / \mathrm{kg})$. During the neutralization, protamine $(4 \mathrm{mg} / \mathrm{kg})$ was administered for five minutes through a central venous catheter using a micro-infusion pump to neutralize the heparin. Adverse events potentially related to protamine mediated pulmonary vascular reaction were identified from the cohort when these occurred within 30 minutes of the initiation of protamine, and met one or more of the following criteria: ${ }^{9,10}(1)$ an increase in pulmonary artery pressure of at least $25 \%$, resulting in a decrease in systemic arterial pressure following protamine at $\geq 25 \%$ of baseline, or a decrease of $\geq 10 \%$ requiring inotropic medications or reinstitution of $\mathrm{CPB}$; (2) non-cardiogenic pulmonary edema, defined as any decrease in $\mathrm{PO}_{2}$ requiring an adjustment in ventilatory support; (3) bronchospasm (an elevation of peak inspiratory airway pressures of greater than $5 \mathrm{~mm} \mathrm{Hg}$ ). These events included those that were preceded by pulmonary hypertension, but clinically insignificant elevations of pulmonary pressures were not perceived as events. In all patients, if hemodynamic instability occurred, protamine administration was slowed or temporarily aborted.

\section{Measurement of Main Outcomes}

Pulmonary arterial blood pressure (PAP) was continuously measured via a BD $22 \mathrm{G}$ intravenous indwelling needle placed into the pulmonary artery by a cardiac surgeon at the following five intraoperative time points: $\left(\mathrm{T}_{0}\right)$ baseline, one minute before $\mathrm{CPB}$; $\left(\mathrm{T}_{1}\right)$ one minute pre-protamine start; $\left(\mathrm{T}_{2}\right)$ one minute post-protamine start; $\left(\mathrm{T}_{3}\right)$ three minutes post-protamine start; $\left(\mathrm{T}_{4}\right)$ five minutes postprotamine start. The parameters of Paw, HR, MBP and dynamic lung compliance (Cdyn) were recorded at the following six time points: $T_{1}-T_{4},\left(T_{5}\right) 10$ minutes postprotamine end, and $\left(\mathrm{T}_{6}\right) 20$ minutes post-protamine end.

For the arterial blood gas analysis, the alveolar-arterial gradient $\left(\mathrm{A}-\mathrm{aDO}_{2}\right)$, respiratory index $(\mathrm{RI})$ and oxygenation index (OI) were documented at three time points: $\mathrm{T}_{0}, \mathrm{~T}_{1}$ and $\mathrm{T}_{6}$.

Sample collection and cryopreservation of radial artery blood and right ventricular blood was performed at the $T_{1}$ and $\mathrm{T}_{6}$ time points, respectively. Thromboxane $\mathrm{B}_{2}\left(\mathrm{TXB}_{2}\right)$ and 6-keto-prostatin $\mathrm{F}_{1 \mathrm{a}}\left(6-\right.$-keto- $\left.\mathrm{F}_{1 \mathrm{a}}\right)$ in plasma were detected by enzyme-linked immunosorbent assay (ELISA). The data of adverse reactions of protamine were recorded. 
Routine perioperative data were collected, including age, gender, weight, height, types of operation (ventricular septal defect or atrial septal defect), preoperative EF value, ACT value after protamine neutralization, operation time, CPB time, and aortic cross-clamp time.

\section{Statistical Analysis}

Routine perioperative data were collected and analyzed. Shapiro-Wilk test was used to test if the data were normally distributed. Continuous variables are expressed as mean \pm standard deviation (SD), and compared across groups using one-way analysis of variance (ANOVA). Categorical variables were expressed as the number of patients together with the corresponding percentage of the total group, and analyzed using chi-square tests or Fisher's Exact test.

Assessment of changes over time in hemodynamic indicators, pulmonary inflammatory factors and pulmonary function indexes across groups were performed using repeated-measures ANOVA, with groups $\left(\mathrm{A}_{1}, \mathrm{~A}_{2}, \mathrm{~B}_{1}\right.$ and $\mathrm{B}_{2}$ ) as the between-subject factor and time (with either 2, 3 , or 6 time points, depending on the parameter) as the within-subject factor. Spearman correlation analysis was performed to evaluate the relationship between pulmonary hemodynamic indicators and inflammatory factors. A $P$-value $<0.05$ was considered statistically significant. Statistical analyses were performed using the SPSS software (Version 20, IBM Corp., Armonk, NY, USA).

\section{Results}

\section{Protamine Reaction}

Twenty patients were assigned randomly to each group $\left(\mathrm{A}_{1}, \mathrm{~A}_{2}, \mathrm{~B}_{1}\right.$ and $\left.\mathrm{B}_{2}\right)$. Perioperative demographics and data were similar among the groups (Table 1). A total of nine cases of protamine-induced pulmonary vascular reactions occurred in the four groups, with a total incidence of $11.25 \%$.

In the $\mathrm{B}_{1}$ group, catastrophic pulmonary vasoconstriction responses occurred in the 3 rd minute of protamine infusing in one patient, followed with an abrupt and significant increase in pulmonary artery pressure $\left(\mathrm{PAP}_{\max } 88\right.$ $\mathrm{mmHg}$ ), a slight elevation in airway pressure $\left(\mathrm{Paw}_{\max } 17\right.$ $\mathrm{mmHg})$, a sharp decrease in systemic BP $\left(\mathrm{IBP}_{\min } 50 / 34\right.$ [41] $\mathrm{mmHg}$ ), and the further development of right ventricular distension and bradycardia. With active treatment, the patient was immediately hyperventilated with $100 \%$ oxygen, multiple bolus doses of epinephrine were used to support the heart rate, and pumping with dopamine and

Table I Perioperative Demographics and Data $(n=20)$

\begin{tabular}{|c|c|c|c|c|c|}
\hline \multicolumn{2}{|l|}{ Parameters } & Group $A_{1}$ & Group $\mathbf{A}_{2}$ & Group $\mathbf{B}_{\mathbf{I}}$ & Group $B_{2}$ \\
\hline \multicolumn{2}{|l|}{ Age $(y r)$} & $4.65 \pm 2.64$ & $4.75 \pm 2.99$ & $4.75 \pm 3.40$ & $4.80 \pm 2.91$ \\
\hline \multirow[t]{2}{*}{ Gender } & Male,n (\%) & 13 & 9 & 9 & 10 \\
\hline & $\begin{array}{c}\text { Female,n } \\
(\%)\end{array}$ & 7 & 11 & 11 & 10 \\
\hline \multicolumn{2}{|l|}{ Weight (kg) } & $17.96 \pm 7.89$ & $17.66 \pm 6.44$ & $16.43 \pm 10.17$ & $16.15 \pm 6.98$ \\
\hline \multicolumn{2}{|l|}{ Height $(\mathrm{cm})$} & $109.55 \pm 18.19$ & $107.10 \pm 17.25$ & $100.95 \pm 20.94$ & $98.85 \pm 15.88$ \\
\hline \multirow[t]{2}{*}{ Types of surgery } & VSD, n (\%) & 13 & 13 & 16 & 14 \\
\hline & ASD, n (\%) & 7 & 7 & 4 & 6 \\
\hline \multicolumn{2}{|c|}{ Preoperative EF (\%) } & $68.70 \pm 5.28$ & $67.00 \pm 15.79$ & $68.40 \pm 5.18$ & $66.45 \pm 4.55$ \\
\hline \multicolumn{2}{|c|}{ Operating time (minutes) } & $128.60 \pm 27.74$ & $|24.30 \pm 3| .20$ & $128.40 \pm 20.37$ & $130.15 \pm 39.45$ \\
\hline \multicolumn{2}{|c|}{ CPB time (minutes) } & $44.35 \pm 20.60$ & $48.00 \pm 19.79$ & $52.10 \pm 14.54$ & $55.05 \pm 30.07$ \\
\hline \multicolumn{2}{|c|}{ Aortic crossclamp time (minutes) } & $27.55 \pm 16.92$ & $31.90 \pm 14.96$ & $34.35 \pm|2.8|$ & $36.80 \pm 27.73$ \\
\hline \multicolumn{2}{|c|}{ Postprotamine ACT (seconds) } & $122.35 \pm 10.58$ & $125.50 \pm 12.63$ & $128.35 \pm 9.80$ & $|27.80 \pm| 3.1 \mid$ \\
\hline
\end{tabular}

Notes: Results are presented as mean \pm standard deviation or absolute number of patients; $A_{1}$ group, non-pulmonary hypertension + lidocaine preconditioning group; $A_{2}$ group, non-pulmonary hypertension + normal saline group; $B_{1}$ group, pulmonary hypertension + lidocaine preconditioning group; $B_{2}$ group, pulmonary hypertension + normal saline group; There were 20 cases in each group.

Abbreviations: VSD, ventricular septal defect; ASD, atrial septal defect; EF, ejection fraction; CPB, cardiopulmonary bypass; ACT, activated clotting time. 
milrinone were performed. A protamine-induced pulmonary vasoconstriction reaction occurred in the 3 rd minute of protamine infusion in three patients in the $\mathrm{A}_{2}$ group, and five patients in the $\mathrm{B}_{2}$ group, and the symptoms were pulmonary hypertension, bronchospasm, hypotension and bradycardia. One patient in the $\mathrm{A}_{2}$ group and two patients in the group $B_{2}$ were automatically relieved after half a minute of no interventions, while the rest of the patients received calcium chloride for mild/moderate hypotension, or epinephrine for severe hypotension, and were immediately hyperventilated with $100 \%$ oxygen for hypoxia (Table 2).

There was no statistically significant difference in the incidence of protamine adverse reactions between the four groups $(P>0.05)$, but there was a statistically significant difference in the incidence of protamine adverse reactions between the lidocaine group $\left(\mathrm{A}_{1}\right.$ and $\mathrm{B}_{1}$ groups) and normal saline group $\left(\mathrm{A}_{2}\right.$ and $\mathrm{B}_{2}$ group $)\left(X^{2}=6.135\right.$; Fisher's exact test, $P=0.029$ ).

\section{Intraoperative Hemodynamic Data}

The intraoperative hemodynamic data during neutralization are presented in Table 3. Compared with the $A_{1}$ group, the PAP and Paw in the $A_{2}$ group at the $T_{3}$ time point were significantly higher, while the MAP in the $\mathrm{B}_{2}$ group at the $T_{3}$ time point was significantly lower. Compared with the $\mathrm{B}_{1}$ group, the Paw in the $B_{2}$ group at the $T_{3}$ time point was significantly higher, while the Cydn in the $\mathrm{B}_{2}$ group at the $\mathrm{T}_{3}$ time point was significantly lower. Compared with the $T_{1}$ time point, the PAP and Paw in the $\mathrm{A}_{2}$ and $\mathrm{B}_{2}$ groups at the $\mathrm{T}_{3}$ time point significantly increased, while the Cdyn in the $A_{2}$ and $B_{2}$ groups at the $T_{3}$ and $T_{4}$ time points significantly decreased.

\section{Intraoperative Inflammatory Data}

The intraoperative pulmonary inflammatory data before neutralization and after neutralization are presented in Table 4. Compared with the $T_{1}$ time point, the plasma levels of $\mathrm{TXB}_{2}$ and 6-keto- $\mathrm{PGF}_{1 \mathrm{a}}$ in the radial artery and

Table 2 Clinical Manifestation of Pulmonary Vascular Adverse Reaction and Treatments

\begin{tabular}{|c|c|c|c|c|c|c|}
\hline \multirow{2}{*}{$\begin{array}{l}\text { Case } \\
\text { No. }\end{array}$} & \multicolumn{5}{|c|}{ Manifestation } & \multirow[t]{2}{*}{ Treatment Process } \\
\hline & $\begin{array}{l}\text { PAP baseline } \\
\rightarrow_{\max } \\
(\mathbf{m m H g})\end{array}$ & $\begin{array}{l}\text { Paw baseline } \\
\rightarrow_{\max } \\
(\mathbf{m m H g})\end{array}$ & $\begin{array}{l}\text { Cydn baseline } \\
\rightarrow_{\min } \\
(\mathrm{mL} / \\
\left.\mathrm{cmH}_{2} 0\right)\end{array}$ & $\begin{array}{l}\text { BP baseline } \rightarrow_{\min } \\
(\mathbf{m m H g})\end{array}$ & $\begin{array}{l}\text { HR baseline } \\
\rightarrow_{\text {min }} \\
\text { (beats/ } \\
\text { min) }\end{array}$ & \\
\hline \multicolumn{7}{|c|}{ I case suffered catastrophic pulmonary vasoconstriction responses in group $B_{\mid}$} \\
\hline I & $39 \rightarrow 88$ & $12 \rightarrow \mid 7$ & $\mathrm{II} \rightarrow 9$ & $\mathrm{II} / 2 / 69(85) \rightarrow 50 / 34(4 \mathrm{I})$ & $\mathrm{II} \rightarrow 103$ & $\begin{array}{l}\text { Hyperventilated with } 100 \% \text { oxygen; } \\
\text { Epinephrine: Img; Dopamine: } 3-8 \mathrm{ug} / \mathrm{kg} . \mathrm{min} \\
\text { Milrinone: } 0.5 \mathrm{ug} / \mathrm{kg} . \mathrm{min}\end{array}$ \\
\hline \multicolumn{7}{|c|}{3 cases suffered pulmonary vasoconstriction reaction responses in group $A_{2}$} \\
\hline 2 & $13 \rightarrow 34$ & $13 \rightarrow 30$ & $28 \rightarrow 8$ & $96 / 59(7 I) \rightarrow 66 / 36(48)$ & $94 \rightarrow 83$ & $\begin{array}{l}\text { The symptoms relieved automatically after } \\
\text { half a minute without intervention }\end{array}$ \\
\hline 3 & $17 \rightarrow 30$ & $14 \rightarrow 25$ & $16 \rightarrow 5$ & $105 / 56(83) \rightarrow 80 / 40(56)$ & $116 \rightarrow 94$ & \multirow{2}{*}{$\begin{array}{l}\text { Hyperventilated with } 100 \% \text { oxygen for } \\
\text { hypoxia; Calcium chloride for mild/ } \\
\text { moderate hypotension; Epinephrine for } \\
\text { severe hypotension }\end{array}$} \\
\hline 4 & $17 \rightarrow 44$ & $9 \rightarrow 28$ & $10 \rightarrow 7$ & $\mid 32 / 76(99) \rightarrow 89 / 46(65)$ & $117 \rightarrow 113$ & \\
\hline \multicolumn{7}{|c|}{5 cases suffered pulmonary vasoconstriction reaction responses in group $B_{2}$} \\
\hline 5 & $22 \rightarrow 38$ & $16 \rightarrow 22$ & $15 \rightarrow 3$ & $72 / 39(50) \rightarrow 69 / 37(49)$ & $120 \rightarrow 119$ & \multirow{2}{*}{$\begin{array}{l}\text { The symptoms relieved automatically after } \\
\text { half a minute without intervention }\end{array}$} \\
\hline 6 & $16 \rightarrow 24$ & $14 \rightarrow \mid 8$ & $16 \rightarrow 11$ & $\mid 00 / 64(77) \rightarrow 91 / 51(65)$ & $|44 \rightarrow| 3 \mid$ & \\
\hline 7 & $23 \rightarrow 35$ & $13 \rightarrow 17$ & $19 \rightarrow 11$ & $78 / 48(58) \rightarrow 47 / 34(40)$ & $\mathrm{I} \mid 2 \rightarrow 87$ & \multirow{3}{*}{$\begin{array}{l}\text { Hyperventilated with } 100 \% \text { oxygen for } \\
\text { hypoxia; Calcium chloride for mild/ } \\
\text { moderate hypotension; Epinephrine for } \\
\text { severe hypotension }\end{array}$} \\
\hline 8 & $33 \rightarrow 58$ & $17 \rightarrow 32$ & $10 \rightarrow 5$ & $\mid 25 / 86(I 07) \rightarrow 66 / 43(54)$ & $|3| \rightarrow \mid 22$ & \\
\hline 9 & $35 \rightarrow 48$ & $17 \rightarrow 26$ & $13 \rightarrow 4$ & $82 / 53(68) \rightarrow 66 / 40(5 \mathrm{I})$ & $138 \rightarrow \mid 35$ & \\
\hline
\end{tabular}


Table 3 Intraoperative Hemodynamic Data

\begin{tabular}{|c|c|c|c|c|c|c|}
\hline Time Point & $\mathbf{T}_{1}$ & $\mathbf{T}_{2}$ & $\mathbf{T}_{3}$ & $\mathbf{T}_{4}$ & $T_{5}$ & $\mathbf{T}_{6}$ \\
\hline \multicolumn{7}{|l|}{ PAP $(m m H g)$} \\
\hline$A_{1}$ & $17.30 \pm 4.26$ & $17.40 \pm 4.42$ & $20.60 \pm 6.19$ & $19.65 \pm 4.38$ & - & - \\
\hline $\mathrm{A}_{2}$ & $19.40 \pm 5.60$ & $19.70 \pm 5.62$ & $24.40 \pm 8.46^{\mathrm{Aa}}$ & $21.25 \pm 5.87$ & - & - \\
\hline $\mathrm{B}_{1}$ & $27.75 \pm 7.25$ & $27.05 \pm 6.95$ & $31.40 \pm 15.25$ & $30.45 \pm 9.85$ & - & - \\
\hline $\mathrm{B}_{2}$ & $27.40 \pm 8.31$ & $27.80 \pm 7.98$ & $32.35 \pm 11.24^{\mathrm{a}}$ & $30.30 \pm 9.22$ & - & - \\
\hline \multicolumn{7}{|l|}{ Paw (mmHg) } \\
\hline$A_{1}$ & $|3.80 \pm 2.4|$ & $14.15 \pm 4.87$ & $15.95 \pm 3.28$ & $15.50 \pm 2.43$ & $13.75 \pm 2.43$ & $14.15 \pm 2.43$ \\
\hline $\mathrm{A}_{2}$ & $13.75 \pm 3.18$ & $14.00 \pm 3.08$ & $16.80 \pm 7.67$ & $18.25 \pm 6.54^{\mathrm{Aa}}$ & $13.85 \pm 3.82$ & $14.00 \pm 3.67$ \\
\hline$B_{1}$ & $14.40 \pm 2.06$ & $14.80 \pm 2.73$ & $15.95 \pm 3.62$ & $15.25 \pm 3.09$ & $14.35 \pm 2.28$ & $14.55 \pm 1.85$ \\
\hline $\mathrm{B}_{2}$ & $14.70 \pm 2.89$ & $14.70 \pm 3.13$ & $16.45 \pm 5.48$ & $18.75 \pm 3.56^{\mathrm{Ba}}$ & $14.40 \pm 3.15$ & $14.70 \pm 3.28$ \\
\hline \multicolumn{7}{|c|}{$\mathrm{Cdyn}\left(\mathrm{mL} / \mathrm{cmH}_{2} \mathrm{O}\right)$} \\
\hline$A_{I}$ & $14.30 \pm 4.16$ & $14.35 \pm 3.73$ & $12.55 \pm 4.68$ & $12.05 \pm 4.44$ & $14.90 \pm 4.24$ & $14.45 \pm 4.47$ \\
\hline $\mathrm{A}_{2}$ & $13.65 \pm 5.69$ & $13.30 \pm 5.55$ & $11.45 \pm 4.9^{\mathrm{a}}$ & $10.40 \pm 4.86^{\mathrm{a}}$ & $14.50 \pm 5.17$ & $14.20 \pm 5.04$ \\
\hline$B_{1}$ & $13.10 \pm 4.94$ & $13.05 \pm 4.89$ & $12.85 \pm 4.79$ & $12.05 \pm 5.45$ & $12.95 \pm 4.05$ & $13.95 \pm 5.56$ \\
\hline $\mathrm{B}_{2}$ & $13.60 \pm 3.47$ & $|3.00 \pm 3.5|$ & $11.20 \pm 4.20^{\mathrm{a}}$ & $9.55 \pm 4.07^{\mathrm{Ba}}$ & $13.45 \pm 5.92$ & $13.95 \pm 6.76$ \\
\hline \multicolumn{7}{|l|}{ MAP $(\mathrm{mmHg})$} \\
\hline$A_{l}$ & $73.65 \pm 12.80$ & $77.15 \pm 12.85$ & $81.00 \pm 14.23$ & $81.95 \pm 13.19$ & $75.20 \pm 7.91$ & $73.15 \pm 9.02$ \\
\hline$A_{2}$ & $73.80 \pm 14.15$ & $74.90 \pm 15.12$ & $74.60 \pm 17.17$ & $80.70 \pm 13.55$ & $73.70 \pm 10.28$ & $73.95 \pm 10.63$ \\
\hline $\mathrm{B}_{1}$ & $73.70 \pm 14.54$ & $75.30 \pm 13.63$ & $75.75 \pm 15.63$ & $80.50 \pm 16.22$ & $74.00 \pm 14.64$ & $71.65 \pm 10.46$ \\
\hline $\mathrm{B}_{2}$ & $71.70 \pm 16.59$ & $74.10 \pm 15.33$ & $69.70 \pm 15.99^{A}$ & $76.95 \pm 15.48$ & $71.30 \pm 12.76$ & $71.60 \pm 10.91$ \\
\hline \multicolumn{7}{|l|}{ HR (beats/min) } \\
\hline$A_{1}$ & $112.60 \pm 29.14$ & $114.05 \pm 15.72$ & $112.70 \pm 16.06$ & $111.50 \pm 15.73$ & $114.60 \pm 17.08$ & $112.80 \pm 16.93$ \\
\hline $\mathrm{A}_{2}$ & $|2| .50 \pm \mid 4.65$ & $119.75 \pm 14.29$ & $116.70 \pm 15.60$ & $117.40 \pm 9.96$ & $|\mathrm{I} 6.00 \pm 1| .83$ & $117.85 \pm 11.65$ \\
\hline$B_{1}$ & $115.05 \pm 17.42$ & $1 \mid 5.05 \pm 15.67$ & $112.10 \pm 15.22$ & $114.60 \pm 17.82$ & $114.35 \pm 14.30$ & $113.65 \pm 12.23$ \\
\hline $\mathrm{B}_{2}$ & $123.20 \pm 15.87$ & $120.30 \pm 16.12$ & $119.40 \pm 16.32$ & $117.15 \pm 18.56$ & $119.05 \pm 12.72$ & || $5.55 \pm|4.2|$ \\
\hline
\end{tabular}

Notes: Results are presented as mean \pm standard deviation; $A_{1}$ group, non-pulmonary hypertension + lidocaine preconditioning group; $A_{2}$ group, non-pulmonary hypertension + normal saline group; $B_{1}$ group, pulmonary hypertension + lidocaine preconditioning group; $B_{2}$ group, pulmonary hypertension + normal saline group; There were 20 cases in each group; Significant differences are expressed as follows: Compared with $A_{1}$ group, ${ }^{A} P<0.05$; Compared with $B_{1}$ group, ${ }^{B} P<0.05$; Compared with $T_{1}$ time point, ${ }^{a} P<0.05 ; T_{1}, I$ min pre protamine start; $T_{2}, I$ min post protamine start; $T_{3}, 3$ min post protamine start; $T_{4}, 5$ min post protamine start; $T_{5}$, 10 min post protamine end; $T_{6}, 20$ min post protamine end.

Abbreviations: PAP, pulmonary artery pressure; Paw, airway pressure; Cdyn, dynamic pulmonary compliance; MAP, mean arterial pressure; HR, heart rate.

right atrium in the four groups at the $\mathrm{T}_{6}$ time point decreased. At the $\mathrm{T}_{6}$ time point, the plasma $\mathrm{TXB}_{2}$ level in the $\mathrm{A}_{2}$ and $\mathrm{B}_{2}$ groups was higher than that in the $\mathrm{A}_{1}$ and $\mathrm{B}_{1}$ groups, respectively, while the level of 6-keto-PGF ${ }_{1 \mathrm{a}}$ in the $A_{2}$ and $B_{2}$ groups was lower, respectively.

Spearman correlation analysis was performed to evaluate the relationship between the plasma $\mathrm{TXB}_{2}$ level in the radial artery at the $\mathrm{T}_{6}$ time point and the PAP value at the $\mathrm{T}_{3}$ time point. The Paw value at the $\mathrm{T}_{4}$ time point revealed a (weak) correlation (correlation coefficient $0.44, P=0.000$ and $0.25, P=0.027$, respectfully). Furthermore, the plasma $\mathrm{TXB}_{2}$ level in the right atrium at the $\mathrm{T}_{6}$ time point, the PAP value in the $T_{3}$ time point, and the Paw value in the $\mathrm{T}_{4}$ time point revealed a (weak) correlation (correlation coefficient $0.41, P=0.000$ and $0.30, P=0.007$, respectfully), while there was no correlation between the plasma 6-keto-
$\mathrm{PGF}_{1 \mathrm{a}}$ level in the radial artery or in the right atrium at the $\mathrm{T}_{6}$ time point, the PAP value at the $\mathrm{T}_{3}$ time point (correlation coefficient $0.09, P=0.413$ and $0.2, P=0.85$, respectively), and the Paw value at the $\mathrm{T}_{4}$ time point (correlation coefficient $-0.20, P=0.079$ and $-0.14, P=$ 0.216 , respectively).

\section{Intraoperative Pulmonary Function Data}

Intraoperative pulmonary function data before neutralization and after neutralization are presented in Table 5 . Compared with the $\mathrm{T}_{0}$ time point, the $\mathrm{OI}$ in the $\mathrm{B}_{2}$ group at the $T_{1}$ and $T_{6}$ time points significantly decreased, while the levels of $\mathrm{RI}$ and $\mathrm{A}-\mathrm{aDO}_{2}$ in the $\mathrm{A}_{2}, \mathrm{~B}_{1}$ and $\mathrm{B}_{2}$ groups at the $T_{1}$ time point were significantly higher. However, the levels of $\mathrm{RI}$ and $\mathrm{A}-\mathrm{aDO}_{2}$ in the $\mathrm{B}_{1}$ group at the $\mathrm{T}_{6}$ time point recovered to that in the $T_{0}$ time point. 
Table 4 Intraoperative Inflammatory Data

\begin{tabular}{|c|c|c|c|c|}
\hline \multirow[t]{2}{*}{ Group } & \multicolumn{2}{|c|}{$\mathbf{T}_{\mathbf{I}}$} & \multicolumn{2}{|c|}{$\mathbf{T}_{6}$} \\
\hline & Radial Artery & Right Atrium & Radial Artery & Right Atrium \\
\hline \multicolumn{5}{|c|}{$\mathrm{TXB}{ }_{2}(\mathrm{pg} / \mathrm{mL})$} \\
\hline$A_{1}$ & $4046.07 \pm|358.2|$ & $3800.72 \pm 1367.60$ & $20|5.98 \pm||30.7|^{\mathrm{a}}$ & $1806.45 \pm 669.26^{\mathrm{a}}$ \\
\hline$A_{2}$ & $4062.27 \pm 1297.22$ & $3904.48 \pm 1087.11$ & $2835.11 \pm 1536.47^{\mathrm{Aa}}$ & $2663.43 \pm 1786.04^{\mathrm{Aa}}$ \\
\hline $\mathrm{B}_{\mathrm{I}}$ & $4906.03 \pm 1460.70$ & $4563.12 \pm 1235.46$ & $3085.53 \pm 2092.23^{\mathrm{a}}$ & $2754.69 \pm 1400.07^{a}$ \\
\hline $\mathrm{B}_{2}$ & $46 \mid 8.44 \pm 618.00$ & $4307.31 \pm 1140.12$ & $3532.93 \pm 1535.05^{\mathrm{Ba}}$ & $\left.3|49.82 \pm| 446.4\right|^{\mathrm{Ba}}$ \\
\hline \multicolumn{5}{|c|}{ 6-keto-PGF ${ }_{\text {la }}(\mathrm{pg} / \mathrm{mL})$} \\
\hline$A_{1}$ & $|402.50 \pm 355.6|$ & $1326.95 \pm 344.56$ & $579.50 \pm 142.28^{\mathrm{a}}$ & $568.95 \pm|33.6|^{\mathrm{a}}$ \\
\hline $\mathrm{A}_{2}$ & $1383.90 \pm 325.46$ & $|327.80 \pm 443.2|$ & $480.55 \pm \mid 48.62^{\mathrm{Aa}}$ & $473.30 \pm|45.8|^{\mathrm{Aa}}$ \\
\hline $\mathrm{B}_{\mathrm{I}}$ & $2042.55 \pm 384.75$ & $|828.35 \pm 328.7|$ & $778.95 \pm 165.02^{\mathrm{a}}$ & $667.35 \pm 158.82^{\mathrm{a}}$ \\
\hline $\mathrm{B}_{2}$ & $1882.45 \pm 303.66$ & $1777.95 \pm 525.26$ & $658.40 \pm 155.89^{\mathrm{Ba}}$ & $548.60 \pm 143.73^{\mathrm{Ba}}$ \\
\hline
\end{tabular}

Notes: Results are presented as mean \pm I standard deviation;' $A_{1}$ group, non-pulmonary hypertension + lidocaine preconditioning group; $A_{2}$ group, non-pulmonary hypertension + normal saline group; $B_{1}$ group, pulmonary hypertension + lidocaine preconditioning group; $B_{2}$ group, pulmonary hypertension + normal saline group, 20 cases in each group; Significant differences are expressed as follows: Compared with $A_{1}$ group, ${ }^{A} P<0.05$; Compared with $B_{1}$ group, ${ }^{B} P<0.05$; Compared with $T_{1}$ group, ${ }^{\text {a }} P<0.05$; $T_{1}$, I min pre protamine start; $T_{6}, 20$ min post protamine end.

Abbreviations: $\mathrm{TXB}_{2}$, thromboxane $\mathrm{B}_{2}$; 6-keto-PGF $\mathrm{F}_{\mathrm{a}}$, 6-keto-prostaglandin $\mathrm{F}_{\mathrm{la}}$.

Table 5 Intraoperative Pulmonary Function Data

\begin{tabular}{|c|c|c|c|}
\hline Group & $\mathbf{T}_{\mathbf{0}}$ & $\mathbf{T}_{\mathbf{1}}$ & $\mathbf{T}_{\mathbf{6}}$ \\
\hline Ol (mmHg) & & & $403.60 \pm 126.53$ \\
$\mathrm{~A}_{1}$ & $423.85 \pm 129.91$ & $369.01 \pm 115.22$ & $371.67 \pm 128.45$ \\
$\mathrm{~A}_{2}$ & $422.40 \pm 109.69$ & $359.95 \pm 123.29$ & $378.61 \pm 137.69$ \\
$\mathrm{~B}_{1}$ & $426.93 \pm 101.09$ & $363.87 \pm 148.86$ & $358.12 \pm 139.08^{\mathrm{a}}$ \\
$\mathrm{B}_{2}$ & $426.68 \pm 115.65$ & $349.85 \pm 121.22^{\mathrm{a}}$ & \\
\hline $\mathrm{RI}$ & & & $0.78 \pm 0.70$ \\
$\mathrm{~A}_{1}$ & $0.59 \pm 0.47$ & $0.94 \pm 0.77$ & $0.84 \pm 0.69^{\mathrm{a}}$ \\
$\mathrm{A}_{2}$ & $0.40 \pm 0.31$ & $1.03 \pm 0.92^{\mathrm{a}}$ & $0.79 \pm 0.57$ \\
$\mathrm{~B}_{1}$ & $0.49 \pm 0.44$ & $1.05 \pm 0.94^{\mathrm{a}}$ & $1.08 \pm 0.93^{\mathrm{a}}$ \\
$\mathrm{B}_{2}$ & $0.53 \pm 0.44$ & $1.18 \pm 1.12^{\mathrm{a}}$ & $109.80 \pm 62.49$ \\
\hline $\mathrm{A}_{-\mathrm{aDO}}(\mathrm{mmHg})$ & & & $131.10 \pm 61.70$ \\
$\mathrm{~A}_{1}$ & $88.15 \pm 48.10$ & $143.10 \pm 77.57$ & $128.50 \pm 35.31$ \\
$\mathrm{~A}_{2}$ & $74.40 \pm 40.66$ & $175.40 \pm 95.38^{\mathrm{a}}$ & $145.43 \pm 97.40^{\mathrm{a}}$ \\
$\mathrm{B}_{1}$ & $97.25 \pm 92.04$ & $183.65 \pm 73.04^{\mathrm{a}}$ & $186.47 \pm 112.13^{\mathrm{a}}$ \\
$\mathrm{B}_{2}$ & $102.15 \pm 75.91$ & & \\
\hline
\end{tabular}

Notes: Results are presented as mean \pm I standard deviation; $A_{1}$ group, non-pulmonary hypertension + lidocaine preconditioning group; $A_{2}$ group, non-pulmonary hypertension + normal saline group; $B_{1}$ group, pulmonary hypertension + lidocaine preconditioning group; $B_{2}$ group, pulmonary hypertension + normal saline group, 20 cases in each group; Significant differences are expressed as follows: Compared with $T_{1}$ group, ${ }^{a} P<0.05 ; T_{0}$, baseline (I min before CPB); $T_{1}, I$ min pre protamine start; $T_{6}, 20$ min post protamine end.

Abbreviations: $\mathrm{Ol}$, oxygen index; RI, respiratory index; $\mathrm{A}-\mathrm{aDO}_{2}$, alveolar-arterial oxygen difference.

\section{Discussion}

These results indicate that precondition of lidocaine before the neutralization of heparin may be an effectively prevention to protamine-induced pulmonary vascular reaction during CHD repair. The pulmonary circulation hemodynamic indexes (PAP, Paw and Cydn) of patients receiving lidocaine pre-treatment before heparin neutralization experienced less fluctuations than that of the patients receiving normal saline pre-treatment. Cydn is the ratio of the change in lung volume to the change in pressure over a tidal breath, with the pressure measured at moments of zero flow during breathing; its fall usually implies narrowing of subtending alveoli. Meanwhile, the plasma $\mathrm{TXB}_{2}$ level of patients receiving lidocaine pre-treatment 
was lower than that of patients receiving normal saline pre-treatment, while the level of 6-keto-PGF ${ }_{1 a}$ of patients receiving lidocaine pre-treatment was higher. Postprotamine pulmonary function (OI, RI and $\mathrm{A}-\mathrm{aDO}_{2}$ ) was unchanged, when compared with baseline in patients receiving lidocaine pre-treatment, but this worsened in patients receiving normal saline pre-treatment. $\mathrm{RI}$ is the ratio of $\mathrm{P}(\mathrm{A}-\mathrm{a}) \mathrm{DO}_{2}$ and $\mathrm{PaO}_{2}$ and it can reflect the function of pulmonary ventilation and oxygen exchange. $\mathrm{OI}$ is calculated as (mean airway pressure $\times \mathrm{FiO}_{2} \times 100$ ) $/ \mathrm{PaO}_{2}$, and it reflects the effects of respirator pressure on oxygenation. In addition, lidocaine may not avoid the so-feared catastrophic anaphylactic reactions to protamine.

Severe protamine-mediated pulmonary hypertension is more likely associated with the anaphylactoid reaction. Protamine is known to be immunogenic, and the large complex formed by protamine binds to heparin in a charger-dependent manner, which is also immunogenic. The neutralization of heparin with protamine in patients undergoing CPB procedure activates complement the system through two cascades: first, protamine and protamine/ heparin complexes can directly activate the complement system in the lung through the classical way when protamine was administered into pulmonary circulation; second, contact with the oxygenator surface can activate the complement system through alternate pathways, leading to the generation of anaphylatoxins: complements $\mathrm{C} 3 \mathrm{a}$ and $\mathrm{C}^{2} \mathrm{a}^{11}$ This can directly cause smooth muscle contraction, and the accumulation of platelets and leucocytes activation in the lungs, respectively, ${ }^{12,13}$ and subsequently induce a large number of releases of proteolytic enzymes that could directly cause lung injury and the subsequent increase in reactive oxygen species production, which contributes to the development of lipid peroxidation. ${ }^{14,15}$ As a result, pulmonary vasoconstriction and potential lung injury would likely be mediated through complement-mediated $\mathrm{C}_{5 \mathrm{a}}$-induced $\mathrm{TXA}_{2}$ generation and might thereby result in the development of various cardiovascular adverse effects, such as pulmonary artery pressure elevation, right ventricular/ right atrial pressure elevation, and systemic hypotension. Therefore, the regimen of treatment is to reduce pulmonary artery pressure and inhibit inflammatory responses, in order to reduce the generation of $\mathrm{TXA}_{2}$, which may be useful.

The anti-inflammatory effect of lidocaine is well recognized in literature. These include the inhibition of granulocyte adherence, the inhibition of neutrophil function, including chemotaxis and superoxide anion release, ${ }^{16}$ and the inhibition of the release of cytokines and proteolytic enzymes, ${ }^{17}$ which have a certain protective effect on vascular endothelial cells. Meanwhile, lidocaine is known to inhibit aggregation and the activation of platelets, and decrease the serum concentration of $\mathrm{TXB}_{2} .{ }^{18}$

The present clinical study presented was designed to investigate the potential cardiopulmonary benefits of lidocaine pre-treatment before the neutralization of protamine. The investigators chose the dose of lidocaine $(2 \mathrm{mg} / \mathrm{kg})$ pre-treatment, because previous clinical studies have suggested that this dosage is hemodynamically safe, and that this is the standardized protamine infusion $(4 \mathrm{mg} / \mathrm{kg}$, nondiluted, five minutes) with the use of a micro-infusion pump to eliminate the effect of different concentrations and velocities of protamine on pulmonary circulation. However, the investigators did not want to inconvenience the surgical team for a prolonged period (holding intrapulmonary needle).

Regarding hemodynamic function, the present study indicated that lidocaine pre-treatment before the neutralization of protamine can effectively reduce pulmonary vasoconstriction response, and enhance the resistance of the blood vessel wall to the harmful stimulation of protamine, reducing the stress responses and spasm reaction of the pulmonary vascular and tracheal smooth muscle caused by the direct stimulation of protamine. At the time point of one-minute pre-protamine administration, the values of PAP and Paw were significantly higher in the $A_{2}$ group than that in the $A_{1}$ group, while the values of MAP in the $\mathrm{B}_{2}$ group were significantly lower. Meanwhile, Paw was significantly higher in the $\mathrm{B}_{2}$ group than that in the $B_{1}$ group, while the values of Cydn were significantly lower in the $\mathrm{B}_{2}$ group. Furthermore, when the values of one-minute pre-protamine administration were compared with that of three-minute post-protamine administration, patients in the $A_{2}$ and $B_{2}$ groups exhibited a mean increase in PAP and Paw. Furthermore, when these were compared with the values at three-minute and four-minute postprotamine administration, patients in the $\mathrm{A}_{2}$ and $\mathrm{B}_{2}$ groups exhibited a mean decrease in Cdyn. The differences in pulmonary circulation indexes between the two routes of prevention (lidocaine/normal saline) were even more impressive and clinically relevant when considering the number of patients in each group who experienced advise pulmonary vascular reactions. Although without statistically significant difference, substantially more patients in 
the $A_{2}$ and $B_{2}$ groups ( 3 and 5, respectively) experienced advise pulmonary vascular reactions at this time point, when compared to patients in the $A_{1}$ and $B_{1}$ groups ( 0 and 1, respectively). Furthermore, the incidence of protamine adverse reactions in the lidocaine group $\left(\mathrm{A}_{1}\right.$ and $\mathrm{B}_{1}$ groups) was lower than that in the normal saline group $\left(\mathrm{A}_{2}\right.$ and $\mathrm{B}_{2}$ group).

Regarding pulmonary inflammatory response indexes, the present study indicated that lidocaine pre-treatment before the neutralization of protamine can effectively reduce $\mathrm{TXB}_{2}$ release and increase 6-keto-PG-F $\mathrm{F}_{1 \mathrm{a}}$ generation to inhibit the inflammatory response in the lung. At the time point of the 20th minute post-protamine administration, the plasma $\mathrm{TXB}_{2}$ level in the $\mathrm{A}_{2}$ and $\mathrm{B}_{2}$ groups was higher than that in the $A_{1}$ and $B_{1}$ groups, and the level of 6-keto-PGF $F_{1 a}$ in the $A_{2}$ and $B_{2}$ groups was lower, respectively.

Regarding the pulmonary function, the present study indicated that lidocaine pre-treatment before the neutralization of protamine may improve respiratory function. Even though the baseline values were compared with that at one-minute pre-protamine administration, the values of $\mathrm{OI}$ in the $\mathrm{B}_{2}$ group exhibited a mean increase, and the values of RI and $\mathrm{A}-\mathrm{aDO}_{2}$ in the $\mathrm{A}_{2}, \mathrm{~B}_{1}$ and $\mathrm{B}_{2}$ groups exhibited a mean decrease, but the values of RI and $\mathrm{A}-\mathrm{aDO}_{2}$ in the $\mathrm{B}_{1}$ group at the time point of 20 -min postprotamine administration recovered to baseline.

Limitations of this study include the small sample size and a lack of insight into the mechanisms. We only included patients only with left to right shunts, and the average age is too high as patients included VSD also. Only one patient had life threatening reaction that too in study group which defeats the purpose of pre-treatment. Future studies with larger patient number, as well as laboratory studies in animals and cells will be conducted to further prove our results and to elucidate the mechanism. Also, preoperative tests such as intrapulmonary shunt ratio (QP: QS), pulmonary vascular resistance (PVR) and reactivity to oxygen and nitric oxide (NO) were not performed. In addition, the sample size was not calculated and confirmed according to the sample size in the early stage of the experiment. Since the mechanism of protamine toxicology is relatively unknown (and seemingly complicated), there may be other underlying factors not accounted for in the study. This might also be an example of unknown toxicology.

\section{Conclusions}

After CHD repair, lidocaine pre-treatment before the neutralization of heparin may exert its effect through the inhibition of $\mathrm{TXB}_{2}$ release and generation of 6-keto-PG-F $\mathrm{F}_{1 \mathrm{a}}$, in order to inhibit the inflammatory responses in the lung and pulmonary vasoconstriction responses, which are caused by the direct stimulation of protamine. By reducing the occurrence rate of pulmonary vascular adverse reactions induced by protamine, lidocaine could improve respiratory function, and play a certain role in lung protection.

\section{Acknowledgments}

We are particularly grateful to all the people who have given us help on our article.

\section{Funding}

There is no funding to report.

\section{Disclosure}

The authors declare that they have no competing interests.

\section{References}

1. Chaney MA, Devin Roberts J, Wroblewski K, Shahul S, Gaudet R, Jeevanandam V. Protamine administration via the ascending aorta may prevent cardiopulmonary instability. $J$ Cardiothorac Vasc Anesth. 2016;30:647-655. doi:10.1053/j.jvca.2015.11.014

2. Brück S, Skrabal C, Träger K, Reinelt H. Risk factors for adverse reactions after protamine administration in adult patients undergoing cardiac surgery - a case report and literature review. Anasthesiol Intensivmed Notfallmed Schmerzther. 2014;49:360-366. doi:10.1055/s-0034-1383887

3. Sokolowska E, Kalaska B, Miklosz J, Mogielnicki A. The toxicology of heparin reversal with protamine: past, present and future. Expert Opin Drug Metab Toxicol. 2016;12:897-909. doi:10.1080/ 17425255.2016.1194395

4. Bruins P, Te Velthuis H, Eerenberg-Belmer AJ, et al. Heparinprotamine complexes and C-reactive protein induce activation of the classical complement pathway: studies in patients undergoing cardiac surgery and in vitro. Thromb Haemost. 2000;84:237-243. doi:10.1055/s-0037-1614002

5. Kimmel SE, Sekeres M, Berlin JA, Ellison N. Mortality and adverse events after protamine administration in patients undergoing cardiopulmonary bypass. Anesth Analg. 2002;94:1402-1408. doi:10.1097/ 00000539-200206000-00005

6. Guan Z, Shen X, Zhang YJ, et al. Use of epoprostenol to treat severe pulmonary vasoconstriction induced by protamine in cardiacsurgery. Medicine. 2018;97:e10908. doi:10.1097/MD.0000000000010908

7. Ding XF, Zhong LL, Zhang B, Li J. [Protective effects of lidocaine on hyperoxia-exposed type II alveolar epithelial cells from premature rats]. Zhongguo Dang Dai Er Ke Za Zhi. 2011;13:313-316. [Chinese]

8. Cardiovascular physicians branch of Chinese medical association. Chinese experts agreed on the diagnosis and treatment of pulmonary hypertension associated with congenital heart disease in 2015. Chin J Intervent Cardiol. 2015;23:61-69..

9. Kim JB, Kim JH, Song KS. Catastrophic bronchial spasm due to a severe anaphylactic reaction to protamine. Korean $J$ Thorac Cardiovasc Surg. 2016;49:472-474. doi:10.5090/kjtcs.2016.49.6.472

10. Kimmel SE, Sekeres MA, Berlin JA, Ellison N, DiSesa VJ, Strom BL. Risk factors for clinically important adverse events after protamine administration following cardiopulmonary bypass. $\mathrm{J} \mathrm{Am} \mathrm{Coll} \mathrm{Cardiol.}$ 1998;32:1916-1922. doi:10.1016/S0735-1097(98)00484-7 
11. Morel DR, Zapol WM, Thomas SJ, et al. C5a and thromboxane generation associated with pulmonary vaso- and broncho-constriction during protamine reversal of heparin. Anesthesiology. 1987;66:597-604. doi:10.1097/00000542198705000-00002

12. Cui W, Lapointe M, Gauvreau D, Kalant D, Cianflone K. Recombinant C3adesArg/acylation stimulating protein (ASP) is highly bioactive: a critical evaluation of C5L2 binding and 3T3-L1 adipocyte activation. Mol Immunol. 2009;46:3207-3217. doi:10.1016/j.molimm.2009.08.013

13. Koster A, Fischer T, Praus M, et al. Hemostatic activation and inflammatory response during cardiopulmonary bypass: impact of heparin management. Anesthesiology. 2002;97:837-841. doi:10.1097/00000542-200210000-00014

14. Ramzan R, Michels S, Weber P, et al. Protamine sulfate induces mitochondrial hyperpolarization and a subsequent increase in reactive oxygen species production. $J$ Pharmacol Exp Ther. 2019;370:308-317. doi:10.1124/jpet.119.257725
15. Jastrzebski J, Sykes MK, Woods DG. Cardio-respiratory effects of protamine sulfate in man. Thorax. 1974;29:534-538. doi:10.1136/ thx.29.5.534

16. Cassuto J, Sinclair R, Bonderovic M. Anti-inflammatory properties of local anesthetics and their present and potential clinical implications. Acta Anaesthesiol Scand. 2006;50:265-282. doi:10.1111/j.13996576.2006.00936.x

17. Feng G, Liu S, Wang GL, Liu GJ. Lidocaine attenuates lipopolysaccharide induced acute lung injury through inhibiting NF-kappaB activation. Pharmacology. 2008;81:32-40. doi:10.1159/ 000107792

18. Satoh K, Kamada S, Kumagai M, Sato M, Kuji A, Joh S. Effect of lidocaine on swine lingual and pulmonary arteries. J Anesth. 2015;29:529-534. doi:10.1007/s00540-014-1965-9

\section{Publish your work in this journal}

The International Journal of General Medicine is an international, peer-reviewed open-access journal that focuses on general and internal medicine, pathogenesis, epidemiology, diagnosis, monitoring and treatment protocols. The journal is characterized by the rapid reporting of reviews, original research and clinical studies across all disease areas. The manuscript management system is completely online and includes a very quick and fair peer-review system, which is all easy to use. Visit http://www.dovepress.com testimonials.php to read real quotes from published authors. 